\title{
Suicidal Ideation among Older People by Different Living Arrangement: The Mediating Effect of Pleasurable Activities
}

\author{
Kim, Bora ${ }^{1} \cdot$ Lim $_{\text {Serah }}{ }^{1} \cdot$ Hong, Wontae ${ }^{1} \cdot$ Kim, Heejung $^{2}$ \\ ${ }^{1}$ Master's Student, College of Nursing, Yonsei University, Seoul \\ ${ }^{2}$ Assistant Professor, College of Nursing · Mo-Im Kim Nursing Research Institute, Yonsei University, Seoul, Korea
}

\begin{abstract}
Purpose: The purpose of this study was to examine mediating effects of pleasurable activities on the relationship between depression and suicidal ideation among the elderly moderated by living arrangement such as those living alone (LA) versus those living with others (LWO). Methods: This study is a cross-sectional and correlational design using secondary data analysis of the 2017 Korean National Survey on the Elderly (2,416 for the LA group, and 6,106 for the LWO group). Logistic regression analysis was conducted comparing effects of pleasurable activities on suicidal ideation between the two groups. Results: For suicidal ideation, there were significant differences in suicidal ideation by sex, religion, and senior center visits in the LA group, while the LWO group had no significant differences identified. Both groups showed significantly different associations of suicidal ideation by socioeconomic status, gathering, meaningful interaction, and depression. Senior center visits were statistically significant in the LA group, while there was not significant in the LWO group. Conclusion: Visiting senior centers can reduce suicidal ideation of the LA group. To prevent suicidal ideation of the elderly living alone, mental health specialists should provide community-cooperative environments to address these issues, especially LA elderly.
\end{abstract}

Key Words: Suicidal ideation; Depression; Leisure activities; Aged; Residence characteristics

\section{INTRODUCTION}

\section{Background}

The high suicide rate of older people is quite a serious issue in Korea. Since 2011, the suicide rate of older people aged 65 and over in Korea has been reported to be three or four times higher than the average of Organization for Economic Cooperation and Development countries [1]. Based on recent data, the rate of suicidal ideation, reported by older people in Korea, is $6.7 \%$. In addition, according to 2017 national statistics, the suicide attempt rate among the older adult population is estimated to be $13.2 \%$ [2]. According to previous studies, factors associated with suicidal ideation of older people in Korea can be classified as demographic, physical, psychological, and social: demographic factors include gender, age, and marital status; physical factors, socioeconomic status and living arrangement as well [3-7]. Among the psychological factors, stress and mood disorders were significant risk factors for suicidal ideation $[4,7,8]$. In terms of social factors, the risk factors for suicide were significantly higher among older people who did not participate regularly in social activities, across several spheres: religion, leisure, and charity $[4,8]$.

Among the various risk factors, suicidal ideation and actual attempts share a common risk factor, which is depression; research findings have consistently been reported to reveal depression as the most powerful risk factor for suicide in later life $[4,7,8]$. In addition, according to the 2015 Korea Welfare Panel survey, an older person suffering from depression reports suicidal ideation seven times more frequently than an older person who does not suffer from that depressive mood [4]. Accordingly, to effectively address suicidal ideation among older people who experience depression, it is important to identify preventative factors associated with both depression and suicide of old-

\footnotetext{
Corresponding author: Kim, Heejung https://orcid.org/0000-0003-3719-0111

College of Nursing, Yonsei University, 50 Yonsei-ro, Seodaemun-gu, Seoul 03722, Korea.

Tel: +82-2-2228-3273, Fax: +82-2-2227-8303, E-mail: hkim80@yuhs.ac

Received: Aug 24, 2019 | Revised: Sep 3, 2019 | Accepted: Sep 7, 2019
}

This is an open access article distributed under the terms of the Creative Commons Attribution Non-Commercial License (http://creativecommons.org/licenses/ by-nc/3.0), which permits unrestricted non-commercial use, distribution, and reproduction in any medium, provided the original work is properly cited. 
er people.

Among the various preventative factors, this study focuses on pleasurable activities such as engagement in a leisure pastimes, social group participation, and interaction with family members and acquaintances. There have been a few studies to investigate pleasurable activities' effects on and role in mental health $[9,10]$. There are various types of pleasurable activities that can work to protect older people from the danger associated with suicidal ideation, including learning activities, political activities, religious activities, volunteering, hobbies and leisure pastimes, social group participation and interaction with meaningful persons; the most important to highlight, however, are proper leisure pastimes [11]. These can lead to an active and healthy life physically, socially, and cognitively while contributing to the improvement of mental health by offering relief from negative emotion and excessive distress [11]. Moreover, a stronger connection with meaningful person decreased the likelihood of reporting suicidal ideation among older people [12,13], and participation in social activities, such as gatherings or religious activities have a buffering effect on the relationship between depression and suicidal ideations as experienced by older people $[8,14]$.

Interestingly, pleasurable activities may vary, depending on the living arrangements of older people; who can be grouped into the two categories: those who live alone and those who live with others. Older people who live alone tend to have a relative lack experience with pleasurable activities, such as leisure pastimes or social participation, relative to older people who live with others [15]. Given the strong relationship between living alone depression, as well as the fact that depression has been shown to be related to suicidal ideations especially in older people who live alone [16-18], it is imperative to determine which social factors can reduce depression and suicidal ideation among older people who live alone.

However, the effects of pleasurable activities on the suicidal ideations of older people who live alone were inconsistent [19]. For example, the informal social relationships with relatives, friends and neighbors of older people who live alone had significant associations with the incidence of suicidal ideation, but formal social relationships, such as social group membership, did not have a significant association with suicidal ideation, according to a prior study [19]. It is therefore necessary to identify the effects of various pleasurable activities on the suicidal ideations of older people, according to their living arrangements.

As described previously, suicide is a problem that is affected by various factors, including physical, psychologi- cal, social and environmental factors among older people. As such, a conceptual framework is required to explain this complicated phenomenon. This secondary data analysis was based on the transactional stress and coping model developed by Lazarus and Folkman [20]. This model emphasizes that the interaction of perceived stress and available coping resources determines the quality of the stress adaptation outcome. Selecting relevant variables and proposing the associations were based on the model, that was; depression was conceived of as an influencing factor; suicidal ideation as an outcome of the stress; pleasurable activities as a mediator of the association between depression and suicidal ideations; living arrangement as a moderator; and demographic factors as covariates, depending on review of previous studies (Figure 1) [4,5,7,16-18,21].

As this study deals with sensitive and socially isolated individuals suffering from depression and suicidal ideations, who also live alone, a methodology that relies on secondary data analysis may be useful to spare those sensitive population from discomfort. Further, the data set consists of a representative survey of older people across the country, using stratified extraction, so the results of this study can be generalized across the entirety of Korea's older people. Therefore, this study intends to use a secondary data analysis, using the Korean National Survey on the 2017 Elderly (KNSE) to identify the mediating effect of pleasurable activities on the relationship between depression and suicidal ideations among older people who live alone and older people who live with others.

\section{Objectives}

The aim of this study was to compare, at a national level, depression, suicidal ideation, and pleasurable activities among older people considering living arrangement, such as living along versus living with others, and then to examine the mediating effect of pleasurable activities between depression and suicidal ideation among older people, as moderated by different living arrangements. Specific research questions are as follows:

- Are there different levels of depression, suicidal ideation and pleasurable activities characterizing older people who live alone, compared with those who live with others?

- Does depression show different associations with suicidal ideation among older people, depending on which of the two living arrangements applies?

- How do pleasurable activities have a distinctive mediating effect on the relationship between depression level and suicidal ideations among older people with 


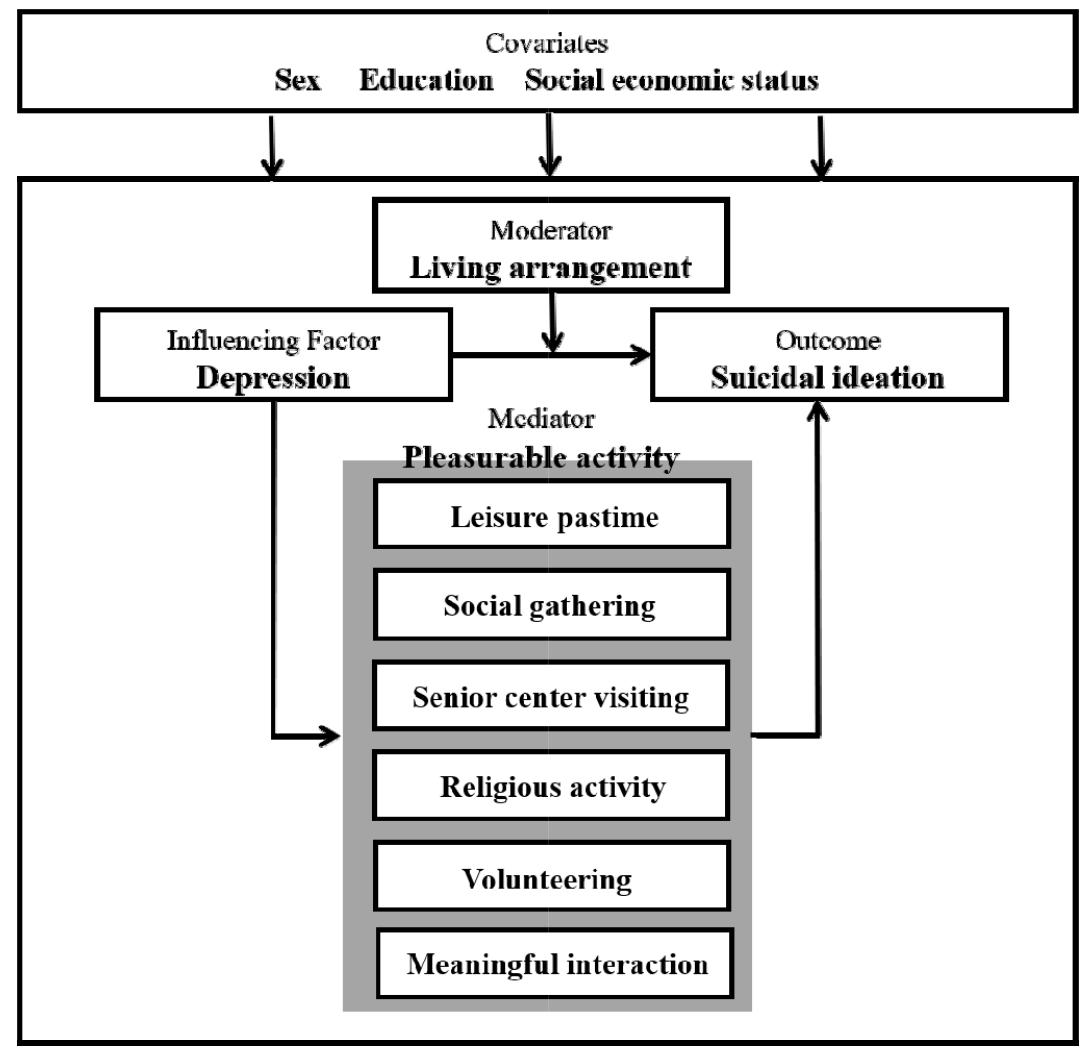

Figure 1. Conceptual framework of this study.

different living arrangements?

- How does living alone have a moderating effect on the relationship between depression level and suicidal ideations among older people?

\section{METHODS}

\section{Study Design}

This study is cross-sectional and correlational in design using a secondary data analysis.

\section{Description of the Primary Data}

The primary data were extracted from the 2017 KNSE [15], which was sponsored by the Ministry of Health and Welfare and Korea Institute for Health and Social Affairs. The target population of the 2017 KNSE survey were individuals, aged 65 years or older, living in non-facility residences in 17 cities and provinces across the country. The primary sampling unit was the $90 \%$ data from the 2010 census and enumeration district (ED) of new apartments, as of the end of 2015, the secondary sampling unit was the household in the ED. The final survey unit consisted of all individuals over the age of 65 years, living in the household. Data were collected between June and August, 2017. The investigators visited all households in the ED and conducted face-to-face interviews with the older people living in each household. The survey focuses on categories of general characteristics, family and social relationships, health, economy, social welfare, and lifestyles of older people [15].

\section{Sample}

The whole sample of raw data consisted of 10,299 people, including 226 proxies, recruited from 934 enumeration districts. In this study, 8,522 older people, aged 65 years or older, who completed the survey by themselves, were selected. They were divided into two groups, depending on their living arrangements, whether they were living with others $(n=6,106)$ or alone $(n=2,416)$. The exclusion criteria were: (1) proxy responses and (2) those who did not complete the survey.

\section{Variables}

\section{1) Suicidal ideation}

Suicidal ideation is a preceding concept that refers to planning, thinking about or considering suicide $[7,8]$ and 
was selected as a dependent variable in this study. The question, "Have you ever thought of suicide since you were 60 years old?" was used to identify the presence of suicidal ideation. The Korea health panel survey and the Korea welfare panel survey also investigated the suicidal ideation with a single question similarly [4,6]. In this study, answering this question, 'yes' defined participants as having suicidal ideation (coded as number 1 ), and the answer 'no' as not having suicidal ideation (coded as number 0$)$.

\section{2) Depression}

Depression is a mood disorder, accompanied by sadness, negative self-esteem, loss of interest in life, loss of sleep and appetite [8] and was selected as an independent variable in this study. In the original survey, a short form of the Geriatric Depression Scale, translated into Korean (SGDS-K), was used to assess depression. The SGDS-K involved a 15-item scale extracted from the GDS, and used as an efficient and effective screening measure of depression. In a study of elderly patients in Korean, the SGDS-K was determined to have good internal consistency reliability (Cronbach's $\alpha=.86$ ), content and discriminant validity, and was also found to be correlated highly overall with GDS-K ( $\mathrm{r}=.95)$. In addition, SGDS-K was found to be a good diagnostic instrument for depression [22]. The optimal cut point of SGDS-K presented in the preceding research [22] is 8 out of a total possible score of 15 , accordingly, this study defined the level of depression in two groups (those who scored between score 0 and score 7 were in the low level of depression group and those who scored between score 8 and score 15 were in the high level of depression group), and the total score of the scale was also verified in the form of continuous variables.

\section{3) Living arrangement}

Living arrangement was selected as a moderator in this study. In the original survey, the investigators visited households and classified types of older people's households as one-person households, elderly couple households (even if one member of the couple was not aged 65 or older), households living with child, grandchild, or relative, and other types. In this study, we defined the living arrangement of each participant as belonging to one of two groups: living alone (coded as number 0 ) and living with others (coded as number 1).

\section{4) Pleasurable activities}

Pleasurable activities were selected as mediators in this study, based on previous studies' operationalization $[8$,
11-14]. A lack of pleasurable activities was coded as number 1 , while participation in any pleasurable activities, such as a leisure pastimes, attending social gathering, visiting a senior center, religious activity, or volunteering for the past year, was coded as number 0. Meaningful interaction, as one of the possible pleasurable activities, was recognized by the number of significant persons, such as siblings, relatives, friends and neighbors. Here, 'no one' was coded as number 1 , and 'at least one' was coded as number 0 .

\section{5) General characteristics}

Sex, education level, and socioeconomic status were selected as covariates in this study depending on review of previous studies $[4,5,7,16-18,21]$. Sex was dichotomized as male (coded as number 1 ) and female (coded as number 0 ), education level classified into no school attended (coded as number 1), and at least primary school attended (coded as number 0 ). Socioeconomic status was differentiated into 3 categories: high (coded as number 2 and designated as a reference for logistic regression), middle (coded as number 1 ) and low (coded as number 0 ).

\section{Procedure}

The systematic missing data for the independent and dependent variables were less than $5 \%$, to ensure quality of data and generalizability of the research results. There were no missing data for most variables. The responses that were automatically omitted, on the basis of prior and connected prior questions were recoded, considering the logical consistency. For example, the response to the question "How many people are you close to?" was omitted if the response for the connected prior question "Is there anyone close to you?" was "no". In those cases, the responses were recoded as number 1.

Prior to analysis, univariate normality and diagnostic testing for multicollinearity were checked. For preliminary analyses, multivariate logistic regression models were used to evaluate the association of suicidal ideation with depression, pleasurable activities variables, sociodemographic characteristics among older people who lived alone and those who lived with others. Based on the results of the initial preliminary models, including the Durban-Watson statistic, the independent variables that represented a threat to multicollinearity were removed; these included age, marital status, subjective heath status, time to watch TV and radio, whether to participate in any learning activities, political groups and hobby clubs, and frequency of contact with friends and relatives. Finally, 11 
independent variables were finally selected, including sex, education level, socioeconomic status, depression, leisure pastimes, social gathering, senior center visiting, religious activity, volunteering, meaningful interaction with significant person, based on correlation coefficients from results of multicollinearity diagnostic tests, including tolerance values, variance inflation factor values lower than 2, and condition indices estimated as 13.25.

\section{Data Analysis}

Since the 2017 KNSE used the stratified two-stage cluster sampling method, a complex sample analysis plan file reflected the cluster variable (the estimation of household), the weight values (the estimation of household members) were considered for complex sample analysis. All statistical analyses were conducted using IBM SPSS Version 25.0 with the significance level set at 0.05 , twotailed.

To examine $1^{\text {st }}$ and $2^{\text {nd }}$ research questions, complex sampling descriptive analyses (independent $t$ tests and chi- squared statistics) were conducted to compare the levels of depression, suicidal ideation and pleasurable activities across the two groups, according to distinctive living arrangements. The correlation between the variables (general characteristics, pleasurable activities) and the suicidal ideation, according to the living arrangement, was identified by complex sampling cross tabulation analysis (chi- squared statistics). To examine $3^{\text {rd }}$ and $4^{\text {th }}$ research questions, a binary logistic regression analyses with complex sample was conducted to examine relationships between depression, pleasurable activities and suicidal ideation among older people who lived alone and those who lived with others, controlling for demographic characteristics. Additionally, logistic regression analysis were conducted to compare different effects of pleasurable activities on suicidal ideation among older people, comparing those who lived alone with those who lived with others.

\section{Ethical Consideration}

There was no personal information that required protection of anonymity and confidentiality for the participants; thus, all data were de-identified. The data of the 2017 KNSE were obtained, with permission to use the data from the Korea Institute for Health and Social Affairs [15]. The survey of primary data corresponds to the National Statistical Office's approval number No. 11771, and this study was exempt from full review of the institutional re- view board (IRB no. Y-2019-0087). Gender-based matching was not used for select the samples, but the differences of study variables were identified.

\section{RESULTS}

1. General Characteristics, Pleasurable Activities, Suicidal Ideation and Depression of the Sample

Table 1 presents general characteristics including socio-demographics, pleasurable activities and suicidal ideation of the sample. Based on the weighted sample, 51.8\% were females and $21.7 \%$ had no education. Approximately $30 \%$ of the respondents reported their socioeconomic status (SES) as high, $35.5 \%$ as middle and $35.1 \%$ as low. In the pleasurable activities categories, the percentage of older people who participated in leisure pastimes or social gathering was $85.8 \%$ and $47.3 \%$, respectively. The percentage of older people who participated in religious activity, senior center, or volunteering was $60.3 \%, 30.2 \%$ and $4.0 \%$ respectively, while $64.6 \%$ of the respondents participated in meaningful interaction with significant persons.

Table 2 presents a comparison of the depression of older people based on different living arrangements. Based on the weighted sample, about $20 \%$ of older people reported high levels of depression and the mean score of depression was about 4 across the overall respondents.

\section{Group Comparison of Characteristics by Living Arrangements}

Most of the characteristics of respondents who lived alone were different from the characteristics of those who lived with others. Relative to those who lived with others, the majority of those who lived alone were female $(80.6 \%)$, had a greater proportion without education $(40.1 \%)$, and self-reported lower SES (44.5\%) (all $p<.001)$. Those who lived alone participated more in religious $(65.6 \%)$ and senior center (38.8\%) activities, but participated in less of social gathering $(31.8 \%)$, volunteering $(3.2 \%)$, meaningful interactions with significant persons $(68.5 \%)$ than those who lived with others. People who lived alone were more likely to report suicidal ideation (10.6\%) than those living with others (5.1\%) (Table 1) and more likely to feel depressed (30.2\%) than those living with others (16.5\%) (all $p<.001)$ (Table 2). The mean score of depression was higher in the living alone group (5.16) than in the living with others group (3.52), and this distinction was also statistically different $(p<.001)$ (Table 2). 
Table 1. Comparison of General Characteristics and Study Variables by Different Living Arrangement

\begin{tabular}{|c|c|c|c|c|c|c|}
\hline \multirow{2}{*}{ Variables } & \multirow{2}{*}{\multicolumn{2}{|c|}{ Categories }} & \multirow{2}{*}{$\begin{array}{c}\text { Overall } \\
\text { Weighted \% }\end{array}$} & \multirow{2}{*}{$\begin{array}{l}\text { Living alone } \\
\text { Weighted \% } \\
\end{array}$} & \multirow{2}{*}{$\frac{\text { Living with others }}{\text { Weighted } \%}$} & \multirow{2}{*}{$p$} \\
\hline & & & & & & \\
\hline \multirow{7}{*}{$\begin{array}{l}\text { General } \\
\text { characteristics }\end{array}$} & Sex & Male & 48.2 & 19.4 & 59.6 & $<.001$ \\
\hline & & Female & 51.8 & 80.6 & 40.4 & \\
\hline & Education & No school attended & 21.7 & 40.1 & 14.4 & $<.001$ \\
\hline & & $\begin{array}{l}\text { At least primary school } \\
\text { attended }\end{array}$ & 78.3 & 59.9 & 85.6 & \\
\hline & Socioeconomic & High & 29.4 & 22.3 & 32.3 & $<.001$ \\
\hline & status & Middle & 35.5 & 33.2 & 36.3 & \\
\hline & & Low & 35.1 & 44.5 & 31.4 & \\
\hline \multirow{6}{*}{$\begin{array}{c}\text { Pleasurable } \\
\text { activities }^{\dagger}\end{array}$} & \multicolumn{2}{|l|}{ Leisure pastimes } & 85.8 & 86.3 & 85.6 & .429 \\
\hline & \multicolumn{2}{|l|}{ Social gathering } & 47.3 & 31.8 & 53.4 & $<.001$ \\
\hline & \multicolumn{2}{|c|}{ Religious activity } & 60.3 & 65.6 & 58.2 & $<.001$ \\
\hline & \multicolumn{2}{|c|}{ Senior center visiting } & 30.2 & 38.8 & 26.8 & $<.001$ \\
\hline & \multicolumn{2}{|l|}{ Volunteering } & 4.0 & 3.2 & 4.3 & .019 \\
\hline & \multicolumn{2}{|c|}{ Meaningful interaction } & 64.6 & 68.5 & 63.0 & $<.001$ \\
\hline \multicolumn{3}{|l|}{ Suicidal ideation } & 6.6 & 10.6 & 5.1 & $<.001$ \\
\hline
\end{tabular}

${ }^{\dagger}$ Multiple responses available.

Table 2. Comparison of Depression by Different Living Arrangement

\begin{tabular}{|c|c|c|c|c|c|c|c|}
\hline \multirow[b]{2}{*}{ Variable } & \multicolumn{2}{|c|}{ Overall } & \multicolumn{2}{|c|}{ Living alone } & \multicolumn{2}{|c|}{ Living with others } & \multirow[b]{2}{*}{$p$} \\
\hline & $\mathrm{n}$ & $\begin{array}{c}\text { Weighted \% or } \\
\quad \mathrm{M} \pm \mathrm{SD}\end{array}$ & $\mathrm{n}$ & $\begin{array}{l}\text { Weighted \% or } \\
\qquad \mathrm{M} \pm \mathrm{SD}\end{array}$ & $\mathrm{n}$ & $\begin{array}{l}\text { Weighted \% or } \\
\qquad \mathrm{M} \pm \mathrm{SD}\end{array}$ & \\
\hline High ( $\geq$ score 8 ) & 1,796 & 20.4 & 747 & 30.2 & 1,049 & 16.5 & $<.001$ \\
\hline Low (< score 8) & 6,801 & 79.6 & 1,805 & 69.8 & 4,996 & 83.5 & $<.001$ \\
\hline Sum score & 8,522 & $3.98 \pm 4.07$ & 2,416 & $5.16 \pm 4.41$ & 6,106 & $3.52 \pm 3.83$ & $<.001$ \\
\hline
\end{tabular}

\section{Group Comparison of Suicidal Ideation and Rele- vant Factors by Living Arrangements accord- ing to Characteristics}

Table 3 presents the percentage of suicidal ideation among the older people with different living arrangements, by general characteristics and pleasurable activities. In this sample, $6.6 \%$ of them admitted to having suicidal ideation since the age of 60 years. There were differences in the suicidal ideation between older people who lived alone and those who lived with others, in terms of sex, SES, and some pleasurable activities (gathering, religious, senior center visiting, and meaningful interactions with others). Among those who lived alone, there were significant differences of suicidal ideation according to sex $\left(x^{2}=25.24, p<.001\right)$, religious activity $\left(x^{2}=10.64, p=.013\right)$ and senior center visiting $\left(x^{2}=17.78, p<.001\right)$, whereas those who lived with others did not show such differences. In both groups, participants, those who lived alone and those who lived with others, showed significant differences in suicidal ideation, according to SES (both showed $p<.001)$, gathering $(p=.003, .012)$, meaningful interaction with others $(p=.030,<.001)$ and depression (both showed $p<.001$ ).

Table 4 presents the results of logistic regression in a composite sample to identify factors affecting the participants' suicidal ideation. The suicidal ideation of the regression model (Nagelkerke $\mathrm{R}^{2}$ ) was .16 in the living alone group and 14 in the living with others group used in the logistic regression model. As a result, senior center visiting was statistically significant in the living alone group $(p=.010)$, whereas it was not in the living with others group. To explain suicidal ideation according to the odds ratio for pleasurable activities categories, suicidal ideation 
Table 3. Suicidal Ideation of Older People with Different Living Arrangements by Characteristics

$(N=8,522)$

\begin{tabular}{|c|c|c|c|c|c|c|c|c|}
\hline \multirow{4}{*}{ Variables } & \multirow{4}{*}{ Categories } & & \multicolumn{3}{|c|}{ Living alone $(n=2,416)$} & \multicolumn{3}{|c|}{ Living with others $(n=6,106)$} \\
\hline & & & \multicolumn{2}{|c|}{ Suicidal ideation } & \multirow{3}{*}{$x^{2}(p)$} & \multicolumn{2}{|c|}{ Suicidal ideation } & \multirow{3}{*}{$x^{2}(p)$} \\
\hline & & & No & Yes & & No & Yes & \\
\hline & & & Weighted \% & Weighted \% & & Weighted \% & Weighted \% & \\
\hline \multirow{7}{*}{$\begin{array}{l}\text { General } \\
\text { characteristics }\end{array}$} & Sex & Male & 83.2 & 16.8 & 25.24 & 95.2 & 4.8 & 1.44 \\
\hline & & Female & 90.9 & 9.1 & $(.001)$ & 94.5 & 5.5 & $(.276)$ \\
\hline & Education & No school attended & 89.9 & 10.1 & 0.45 & 93.8 & 6.2 & 2.79 \\
\hline & & School attended & 89.1 & 10.9 & $(.550)$ & 95.1 & 4.9 & $(.138)$ \\
\hline & Socioeconomic & High & 95.7 & 4.3 & 91.98 & 97.6 & 2.4 & 134.48 \\
\hline & status & Middle & 93.9 & 6.1 & $(<.001)$ & 96.7 & 3.3 & $(<.001)$ \\
\hline & & Low & 82.9 & 17.1 & & 90.1 & 9.9 & \\
\hline \multirow{12}{*}{$\begin{array}{c}\text { Pleasurable } \\
\text { activities }\end{array}$} & Leisure & Yes & 89.6 & 10.4 & 0.50 & 95.1 & 4.9 & 2.48 \\
\hline & pastimes & No & 88.3 & 11.7 & $(.494)$ & 93.9 & 6.1 & $(.163)$ \\
\hline & Gathering & Yes & 92.8 & 7.2 & 14.43 & 95.7 & 4.3 & 7.91 \\
\hline & & No & 87.8 & 12.2 & $(.003)$ & 94.1 & 5.9 & $(.012)$ \\
\hline & Religious & Yes & 90.9 & 9.1 & 10.64 & 94.8 & 5.2 & 0.23 \\
\hline & activity & No & 86.7 & 13.3 & $(.013)$ & 95.1 & 4.9 & $(.645)$ \\
\hline & Senior center & Yes & 92.6 & 7.4 & 17.78 & 95.0 & 5.0 & 0.01 \\
\hline & visiting & No & 87.4 & 12.6 & $(<.001)$ & 94.9 & 5.1 & $(.936)$ \\
\hline & Volunteering & Yes & 90.8 & 9.2 & 0.16 & 97.4 & 2.6 & 3.51 \\
\hline & & No & 89.4 & 10.6 & $(.676)$ & 94.8 & 5.2 & $(.070)$ \\
\hline & Meaningful & Yes & 88.6 & 11.4 & 4.27 & 94.2 & 5.8 & 12.85 \\
\hline & interaction & No & 91.3 & 8.7 & $(.030)$ & 96.3 & 3.7 & $(<.001)$ \\
\hline \multirow[t]{2}{*}{ Depression } & Score 8 as cut & High & 78.3 & 21.7 & 143.32 & 83.6 & 16.4 & 317.46 \\
\hline & point & Low & 94.2 & 5.8 & $(<.001)$ & 97.2 & 2.8 & $(<.001)$ \\
\hline
\end{tabular}

of those in the living alone group who visited senior center more than once was 0.67 (95\% CI=0.49 0.94), which is lower than that in the living alone group who did not visit senior center. In other words, suicidal ideation in the living alone group was low for those who visited senior centers. In the living alone group, the suicidal ideation of females was, significantly, 0.58 times lower than males' suicidal ideation (95\% CI=0.39 0.87), while this distinction between the sexes did not obtain among those who lived with others. In both groups, low SES and depression were statistically significant (all $p<.001$ ).

\section{DISCUSSION}

Our study findings provide important information about the related factors of suicidal ideation identified among older adults who live alone and who live with others, focusing specifically on the mediating effects of pleasurable activities. In this study, the older people who lived alone showed a high proportion of females, low educa- tional attainment, low SES, increased levels of depression, and a high probability of suicidal ideation, relative compared to the older people who lived with others. This findings results from the trends of women having an average life expectancy of 85.7 years, longer than men's 79.7 years [23]. In addition, most older people often live alone as their children formulate nuclear family for education or work, thus they often suffer financial difficulty secondary to weakening family support. Particularly those living alone with low education or SES tend to retire quickly [24], so this may worsen financial difficulties, social isolation and depression. In addition, the low SES and increased levels of depression were related to the increased probability of suicidal ideation across both groups. These results are consistent with the characteristics of the older people who lived alone, as specified generally by previous studies $[4,5,7,16-18,21]$. As indicated by the stress and coping model, depression acts as an aggravating factor on the suicidal ideation among older people, and a given living arrangement acts as a moderator. According to the con- 
Table 4. Factors associated with Suicidal Ideation among Older Adults with Different Living Arrangements

$(N=8,522)$

\begin{tabular}{|c|c|c|c|c|}
\hline \multirow{2}{*}{ Variables } & \multicolumn{2}{|c|}{ Living alone $(\mathrm{n}=2,416)$} & \multicolumn{2}{|c|}{ Living with others $(n=6,106)$} \\
\hline & OR $(95 \% \mathrm{CI})$ & Wald F $(p)$ & OR $(95 \% \mathrm{CI})$ & Wald F $(p)$ \\
\hline \multicolumn{5}{|l|}{ General characteristics } \\
\hline Sex (ref. male) & $0.58(0.39 \sim 0.87)$ & $6.99(.008)$ & $1.05(0.78 \sim 1.40)$ & $0.09(.768)$ \\
\hline $\begin{array}{l}\text { Education (ref. no school attended) } \\
\text { School attended }\end{array}$ & 1.32 (0.98 1.78) & $3.41(.065)$ & $1.12(0.77 \sim 1.63)$ & $0.35(.555)$ \\
\hline $\begin{array}{l}\text { Socioeconomic status (ref. high) } \\
\text { Middle } \\
\text { Low }\end{array}$ & $\begin{array}{l}1.40(0.81 \sim 2.42) \\
3.10(1.93 \sim 4.99)\end{array}$ & $16.80(<.001)$ & $\begin{array}{l}1.13(0.72 \sim 1.77) \\
2.75(1.81 \sim 4.15)\end{array}$ & $25.06(<.001)$ \\
\hline \multicolumn{5}{|l|}{ Depression (ref. low < score 8) } \\
\hline High $(\geq$ score 8$)$ & $3.56(2.50 \sim 5.05)$ & $50.19(<.001)$ & $5.54(4.06 \sim 7.56)$ & $117.15(<.001)$ \\
\hline \multicolumn{5}{|l|}{ Pleasurable activities } \\
\hline $\begin{array}{l}\text { Leisure (ref. no leisure pastimes) } \\
\text { Do more than one leisure pastimes }\end{array}$ & $1.40(0.96 \sim 2.04)$ & $3.02(.083)$ & $1.10(0.77 \sim 1.58)$ & $0.28(.595)$ \\
\hline $\begin{array}{l}\text { Gathering (ref. no attended) } \\
\text { Attend gathering more than once }\end{array}$ & $0.77(0.51 \sim 1.16)$ & $1.58(.209)$ & $1.32(0.99 \sim 1.75)$ & $3.53(.061)$ \\
\hline $\begin{array}{l}\text { Religious activity (ref. no religion) } \\
\text { Have religion }\end{array}$ & $0.76(0.55 \sim 1.07)$ & $2.51(.113)$ & $1.21(0.92 \sim 1.58)$ & $1.85(.174)$ \\
\hline $\begin{array}{l}\text { Senior center visiting (ref. no visited) } \\
\text { Visit senior center more than once }\end{array}$ & $0.67(0.49 \sim 0.94)$ & $6.73(.010)$ & $1.12(0.81 \sim 1.54)$ & $0.45(.503)$ \\
\hline $\begin{array}{l}\text { Volunteer (ref. no experience) } \\
\text { Do volunteering more than once }\end{array}$ & $1.47(0.66 \sim 3.28)$ & $0.89(.346)$ & $0.68(0.31 \sim 1.51)$ & $0.89(.345)$ \\
\hline $\begin{array}{l}\text { Meaningful interaction (ref. no interaction) } \\
\text { Interaction with more than one person }\end{array}$ & $0.82(0.60 \sim 1.12)$ & $1.61(.205)$ & $1.05(0.81 \sim 1.36)$ & $0.11(.740)$ \\
\hline Cox and Snell $\mathrm{R}^{2}$ & & & & \\
\hline Nagelkerke $\mathrm{R}^{2}$ & & & & \\
\hline
\end{tabular}

Reference group for suicidal ideation variable: no suicidal ideation=0; $\mathrm{OR}=\mathrm{odds}$ ratio; $\mathrm{CI}=$ confidence interval.

ceptual framework, pleasurable activities were included as a mediator of the association between depression and suicidal ideation. As the results indicate, among those pleasurable activities, visiting the senior center was proven to have a significant impact.

Each pleasurable activity of the older people who lived alone and those who lived with others had inconsistent impacts on suicide ideation. Those who lived alone participated more in religious activities and visits to the senior center, while less in social gathering and volunteering than those who lived with others. In addition, visiting senior centers had a significant effect on reducing suicidal ideation among those who lived alone. Dissimilar to social gathering, visiting senior centers can be more beneficial to mental health as they are productive and pleasurable activities, including the professional services such as health promotion and welfare support [25]. The interaction with professionals in those facilities may also helpful. In terms of clinical implications, as visiting senior centers was related to reduced suicidal ideation among those who lived alone, it seems necessary implement a link between those who live alone to the relevant senior center and to activate the programs which may be helpful to those who live alone within the senior center to reduce the suicidal ideation among those who live alone. Older people have the opportunity to expand their informal support system, prevent themselves from experiencing a sense of isolation from the community, strengthen bonds among contemporaries and share information through visiting senior centers [26]. Those who live alone, however, may face limitations on their ability to visit the senior center, due to poor accessibility, lack of information, or limited mobility. Recently, a commission from the Ministry of Health and Welfare reviewed the reorganization of senior center serv- 
ices to expand the function of counseling and strengthen case management by facilitating connections to local resources for the older people who live alone [26]. In addition, the commission promoted 'visiting performance of culture and art' and education programs, in conjunction with the senior centers, for older people who live alone, to encourage their use of senior center services and provide various opportunities for participation in social activities, such as gardening, to prevent isolation and depression [26]. At the same time, the community should cultivate an atmosphere that encourages visits to the senior centers so encourage older people who live alone to become interested in visiting the senior centers and enjoying a pleasant experience.

Some previous studies $[8,11,14]$ reported that engaging in a leisure pastimes and gathering with other people can reduce suicidal ideation among older people; however, interestingly, the effects of those activities on suicidal ideation were not statistically significant in this study. Meaningful interactions, such as connections with family or relationships with friends, are regarded as having a significant effect on reducing suicidal ideation among older people $[12,13]$. Interaction with a meaningful person means the existence of a person who listen to the older person [15], and awareness of the existence of a person who cares deeply can be helpful for maintaining mental health [12, 13], but the result was not significant in this study. It is possible that high levels of depression and the experience of living alone have interaction effects that work to decrease the force of pleasurable activities, thereby reducing their impact dissimilar to those of the previous studies $[8,11,14]$. Moreover, the degree of participation in pleasurable activities, such as information about frequency of participation, was not included in this study. Dichotomized information (yes or no) imposes limitations on verifying the extent to which participation was active; further studies should incorporate consideration of more details about frequency or quality of participation in each activity.

Low SES played an important role in the suicidal ideation among the older people in both groups, those who lived alone and those who lived with others as described in the previous studies $[17,18]$. According to a prior study [7], financial difficulty was significantly related to suicidal ideation among those with low SES, and, in particular, males with low SES were at higher risk of suicidal ideation, than females, among older people. The rationale behind understanding males as vulnerable to suicidal ideation can be found in other prior studies [6,27], and has been proven in this study. In this study, male suicidal ideation was significantly higher than female, especially for those in the living alone group, which reflects the need for intervention to enhance the mental health of older people with low SES who live alone, particularly among males. It is necessary to investigate the mental health of older people who live alone, with low SES, to develop social welfare services aimed at preventing suicidal ideation. Older men who live alone are likelier to experience multiple difficulties, as they typically lack the ability to handle daily problems, such as preparing meals and cleaning house, relative to females $[7,27]$. Once economic difficulties are added to this picture, the possibility of suicidal ideation may be even higher. As a result, an objective survey should be conducted to determine the status of older people who live alone and their need for welfare services. In addition, the scope of welfare services aimed at protecting older people who live alone should be expanded, and the mental health management area must be strengthened in terms of the contents of such services. Programs can also be provided to encourage participation in social activities that are intended to help and support older people who live alone. Furthermore, it is necessary to create a foundation for providing professional suicide prevention services by actively utilizing resources such as cooperative system among community-oriented institutions for preventing the suicide of older people, excavation and database establishment of high-risk mental health in older people, education centered on older people care, and training for suicide prevention specialists [4-7]. In addition, the government should develop a standardized measurement of depression and suicidal risk, also distribute manuals for suicide prevention, so that many people can pay attention to the promotion of mental health and suicide prevention among the older people alone $[4,16]$.

There were several limitations in this study, which relied on a secondary data analysis, as well as cross-sectional survey data. First, it was unable to include any variables that reflected the influence of changes in living arrangements or the duration of living alone on suicidal ideation. Longitudinal investigation about any changes in living arrangements or whether data concerning the duration of living alone may be helpful in attaining a more comprehensive understanding of suicidal ideation. In addition, further research should include variables capable of leveraging longitudinal data to differentiate the short-term and long-term effects of living alone. Second, a limited set of variables associated with suicidal ideation were included; this refers to those that were available in the primary data, considering multicollinearity. Hence, further studies may include more extensive information on socio-demographic factors and pleasurable activities associated with sui- 
cidal ideation. Suicidal ideation among older people can be affected by various physical, psychological, social, and environmental factors; therefore, further research is required to confirm the best combination of pleasurable activities to reduce suicidal ideation among older people dwelling in the community, targeting both general and specific situations. Last, variables were selected by the researchers in accordance with the 2017 KNSE, which could lead to misunderstanding that the variables do not appear to be exclusive concepts to each other. Hence, it is worth limiting the interpretation of the results of this study considering the possibility that the survey of 2017 KNSE may not be an exclusive concept.

\section{CONCLUSION}

Our study findings show that pleasurable activities are partially associated with suicidal ideation among older people, relative to different living arrangements. However, different patterns were found between those who live alone and those who live with others. Especially, visiting senior centers has a significant association on reducing suicidal ideation among those who live alone. Further research should focus on the different patterns of suicidal ideation, according to type and frequency of pleasurable activities and the interaction effect with living arrangement or depression. Policy makers and clinicians who seek to enhance older people's health and welfare should understand socio-demographic characteristics and patterns of social participation, such as the extent to which pleasurable activities can prevent suicidal ideation among older people. Thus, community should encourage older people who live alone to visit senior centers to ensure that they can experience the pleasure of social participation, which can help to prevent the development of suicidal ideation. In addition, it is necessary to create community-cooperative environment preventing depression and suicide among older people. By development of education system and training of mental health specialists, it is necessary to identify high-risk mental health in older people living alone.

\section{CONFLICTS OF INTEREST}

The authors declared no conflicts of interest.

\section{ORCID}

Kim, Bora

Lim, Serah

Hong, Wontae

Kim, Heejung https:// orcid.org/0000-0002-7054-1860

https://orcid.org/0000-0002-5510-1031

https://orcid.org/0000-0002-1598-9283

https://orcid.org/0000-0003-3719-0111

\section{REFERENCES}

1. Ministry of Health and Welfare, Korea Suicide Prevention Center. 2019 Suicide prevention white book. Seoul: Korea Suicide Prevention Center; 2019 July. Report No. 11-1352000-00163510.

2. Statistics Korea. Reason and attempt to think suicide by general feature of older persons (over 65 years old) [Internet]. 2017 [cited 2019 Sep 2]. Available from:

http://kosis.kr/eng/search/searchList.do

3. Chang SH, Suh EE, Choi HJ. Risk factors on suicidal ideation and suicidal attempt among community dwelling older adults: based on 2014 community health survey. Korean Journal of Rehabilitation Nursing. 2017;20(2):111-121.

4. Kim JH, Tak YR. Factors influencing suicidal ideation in the elderly: using 2015 Korea welfare panel study. Journal of the Korean Data Analysis Society. 2018;20(2):1051-1062.

5. Lee HK, Kim MS, Choi SS, Choi MK. Eco-systematic analysis on the factors related to the Korean elderly suicide ideation. Health and Social Welfare Review. 2014;34(3):430-451.

6. Park MJ. Suicidal ideation and affecting factors according to sex in elderly by using Korea health panel data 2010. Journal of the Korean Data Analysis Society. 2015;17(2):1087-1099.

7. Lee SW. A longitudinal study on predictors of suicide ideation in old people: using a panel logit model. Health and Social Welfare Review. 2017;31(3):191-229.

8. Kim MI, Shin HR. Influence of depression of the elderly on suicidal ideation: focused on the moderating effect of social participation and preparation for aging. Seoul Studies. 2013;14 (4):185-201.

9. Hershenberg R, Paulson D, Gros DF, Acierno R. Does amount and type of activity matter in behavioral activation? A preliminary investigation of the relationship between pleasant, functional, and social activities and outcome. Behavioural and Cognitive Psychotherapy. 2015;43(4):396-411.

10. Phoenix C, Orr N. Pleasure: a forgotten dimension of physical activity in older age. Social Science \& Medicine. 2014;115:94-102.

11. Shin WW. The study on relationship between physical and psychological health characteristics and life satisfaction of older adults: focused on moderating effect of volunteer participation. Journal of Welfare for the Aged. 2011;54:135-163.

12. Kim MS, Ko JW. The effect of the elderly's leisure activity on their health and the mediating role of family support. Journal of Welfare for the Aged. 2013;60:35-54.

13. Purcell B, Heisel MJ, Speice J, Franus N, Conwell Y, Duberstein PR. Family connectedness moderates the association between living alone and suicide ideation in a clinical sample of adults 50 years and older. The American Journal of Geriatric Psychiatry. 2012;20(8):717-723.

14. Roh HW, Hong $\mathrm{CH}$, Lee $\mathrm{Y}$, Oh BH, Lee KS, Chang KJ, et al. 
Participation in physical, social, and religious activity and risk of depression in the elderly: a community-based three-year longitudinal study in Korea. PLOS One. 2015;10(7):e0132838.

15. Ministry of Health and Welfare, Korea Institute for Health and Social Affairs. Korean national survey on the elderly 2017. Sejong: National Research Complex; 2017 November. Report No. 11-1352000-000672-12.

16. Park JI, Yang JC, Han CS, Park TW, Chung SK. Suicidal ideation among Korean elderly: risk factors and population attributable fractions. Psychiatry. 2016;79(3):262-281.

17. Baek HC, Lee JH. Factors affecting suicidal ideation of the low-income elderly living alone. Journal of Korean Academy of Community Health Nursing. 2014;25(3):180-186.

18. Sohn JN. A study on factors influencing the suicidal ideation in elderly people who live alone or live with family. Journal of Korean Academy of Psychiatric and Mental Health Nursing. 2012;21(2):118-126.

19. Kwon HJ, Jeong JU, Choi M. Social relationships and suicidal ideation among the elderly who live alone in Republic of Korea: a logistic model. INQUIRY: The Journal of Health Care Organization, Provision, and Financing. 2018;55:1-10.

20. Lazarus RS, Folkman S. Stress, appraisal, and coping. New York: Springer; 1984. 456 p.

21. Kim KH, Kim JS, Lee BS, Lee EK, Ahn YM, Choi MH. A study about the factors affecting the suicidal thought in Korean elders. Journal of Korean Academy of Psychiatric and Mental Health Nursing. 2010;19(4):391-399.

22. Bae JN, Maeng JC. Development of the Korean version of the Geriatric Depression Scale and its short form among elderly psychiatric patients. Journal of Psychosomatic Research. 2004; 57(3):297-305.

23. Statistics Korea. Life tables for Korea, 2017. Daejeon: Statistics Korea; 2018 December. Report No. 11-1240000-000293-11.

24. The Economist. A generation of old people is about to change the global economy. They will not all do so in the same way [Internet]. 2014 [cited 2019 Sep 2]. Available from: https://www.economist.com/briefing/2014/04/26/age-inva ders

25. Ministry of Health and Welfare. 2019 Senior health and welfare project II. Sejong: National Research Complex; 2017 November. Report No. 11-1352000-001416-10.

26. Ministry of Health and Welfare. Second comprehensive support plan for the elderly living alone ('18-'22). Sejong: Ministry of Health and Welfare; 2018 April.

27. Cho YU, Han CK. A study on the relationship between depression and suicidal attempt among elderly man living alone in permanent rental housing: analyzing moderating effect of social support. Health and Social Welfare Review. 2014;34(4): 295-320. 